\title{
Europe edges closer to an integrated science policy
}

\section{Quirin Schiermeier, Munich}

The concept of a single 'European research area' last week took another step towards becoming a reality. At a meeting in Luxembourg, the research ministers of the 15 member states of the European Union (EU) fixed a schedule for changes intended to increase the efficiency and competitiveness of basic science in Europe.

The aim is to forge closer links, at both practical and strategic levels, between the scientific activities and science policies pursued by individual member states through their national research agencies.

A number of scientific organizations welcomed the agreement as a major achievement. "What we have here is a clear outline of a true, and urgently needed, joint European science policy," says Enric Banda, secretary general of the European Science Foundation (ESF).

The various measures for establishing the single research area are now set to be implemented by the end of 2001. They include creating a single European patent, compatible benchmarking of national research systems, building a high-speed trans-European research network, removing bureaucratic obstacles to the mobility of researchers, and opening national research programmes to selected transnational research projects.

The resolution is based on a proposal put forward in January by Philippe Busquin, the European Commissioner for research. However, as expected, a second resolution calling on the commission to support the infrastructure costs of Europe-wide lifescience facilities was not endorsed (see Nature 405, 723;2000).

Now that the European research ministers have formally endorsed Busquin's draft, the integration of national and EU research programmes appears to have become a significant practical priority.

Reinder van Duinen, president of the ESF and head of the Netherlands' national research council, says that science and technology are now high on the agenda of Europe's leaders. He is particularly pleased that the research ministers have agreed on well-defined tasks and a strict timetable for their realization. "The fact that there is now a managerial schedule puts European science policy on the same political level as the monetary union, defence or foreign policy," he says.

Richard Brook, chief executive of the British Engineering and Physical Sciences Research Council, similarly applauds Busquin's role in promoting the convergence of Europe's national science bases. He sees the resolution's suggestion of a coherent and comparable system of benchmarking nation-

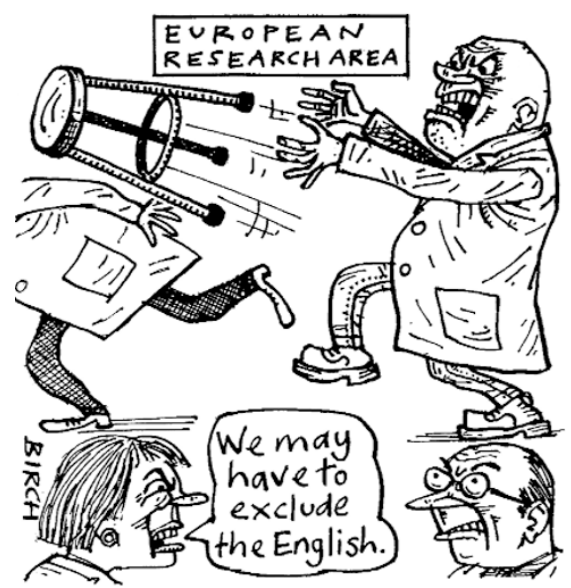

al research performances as a necessary tool for achieving the common research space.

But Brook is also keen to stress that regional research efforts and small-scale collaboration will remain important. Moreover, he points out that, on legal and administrative grounds, national research councils have only limited opportunities to make funds available Europe-wide.

Even if such chances increase, there will be no dramatic overnight change. Indeed, the resolution suggests that the networking of national research programmes should start on a voluntary basis for goals with a European dimension. According to Banda, this matches the objectives of the ESF, which has recently set up its EUROCORES programme to aid collaboration between agencies or research organizations from different countries.

Ernst-Ludwig Winnacker, president of the DFG, Germany's main funding organization for university research, calls the European research area an extremely helpful concept. "Increased networking between national funding agencies is really desirable," he says. "The DFG will do everything it can to help make Busquin's effort a success."

At a press conference following last week's research council meeting, Busquin emphasized the advances in science and technology policy that have been made during the past six months. "Science has finally taken the place in Europe it deserves," he said.

France's new science minister, RogerGérard Schwartzenberg, will next month succeed José Mariano Gago, the Portuguese science minister, as president of the European research council - the body that brings together EU research ministers. Schwartzenberg said last week that he is "fully sympathetic" with the course mapped out by Gago and Busquin.

http://europa.eu.int/comm/research/area.html http://www.esf.org/about/eurocores.htm

\section{UK panel calls for more cuts to carbon dioxide emission}

Natasha Loder, London

Britain should reduce its emissions of carbon dioxide by $60 \%$ over the next 50 years, and set an international model for tackling climate change, according to a key independent report to the UK government published last week.

The Royal Commission on Environmental Pollution, in a report entitled Energy — The Changing Climate, says the United Kingdom has a "moral imperative" to act now to curb emissions. But it also doubts whether the government will be able to meet its target of a $20 \%$ reduction in carbon dioxide emissions in the next decade.

The commission is an independent body that reports to parliament on the crucial environmental issues facing Britain and the world. Its report also reveals that the United Kingdom spends less on energy-related research than almost any other developed nation, and warns the government that it must reverse its trend of cutting spending on such research if new energy systems are to be developed.

"We cannot expect other nations to do their part in countering this threat - least of all if they're much less wealthy - unless we demonstrate we are really serious," says Tom Blundell, head of the department of biochemistry at the University of Cambridge and the commission's chairman. According to Blundell, the UK environment minister, Michael Meacher, agrees that a $60 \%$ reduction is needed in the long term.

Blundell says that more research should be focused on the electricity grid to ensure the effective distribution of high-quality energy, including that of intermittent energy sources such as solar and wind power. The report says Britain lags far behind the rest of Europe in developing renewable-energy technologies.

The report coincides with a new round of discussions in Bonn over the detailed implementation of the Kyoto Protocol on reducing the emission of greenhouse gases. Effective mechanisms for reducing emissions must be finalized in time for a crunch meeting in The Hague this November.

Last week, three environmental groups claimed that some industrialized countries were trying to negotiate looser terms for certain mechanisms in the treaty that would 
undermine its effectiveness.

A number of commentators point out the irony that many of the hotly debated flexible mechanisms are there at the insistence of the United States, which is highly unlikely to ratify the Kyoto Protocol.

The November meeting coincides with the US elections, and the US position is not expected to have changed by then. However, the United States does not have a blocking vote, so the protocol can be implemented without it. The new administration could still instigate mitigation measures if it chose to do so.

But observers point out that Kyoto's $5.2 \%$ target would not be reached without US involvement. Benito Muller, a senior research fellow from the Oxford Institute for Energy Studies, says that although this is "neither here nor there", more substantial steps are needed. "Industrialized nations have committed themselves to showing leadership [on global warming] and Kyoto is the tool by which we can do it," he says.

A continuing source of controversy involves a mechanism that would allow industrialized nations to claim credits against their emissions by investing in clean technologies - such as nuclear power - in developing countries.

The nuclear industry is emphasizing the major role that nuclear energy could play in reducing global warming. But critics, including Britain's Royal Commission, warn that the issue of nuclear waste must be dealt with before it can qualify as a clean technology. http://www.rcep.org.uk/newenergy.html

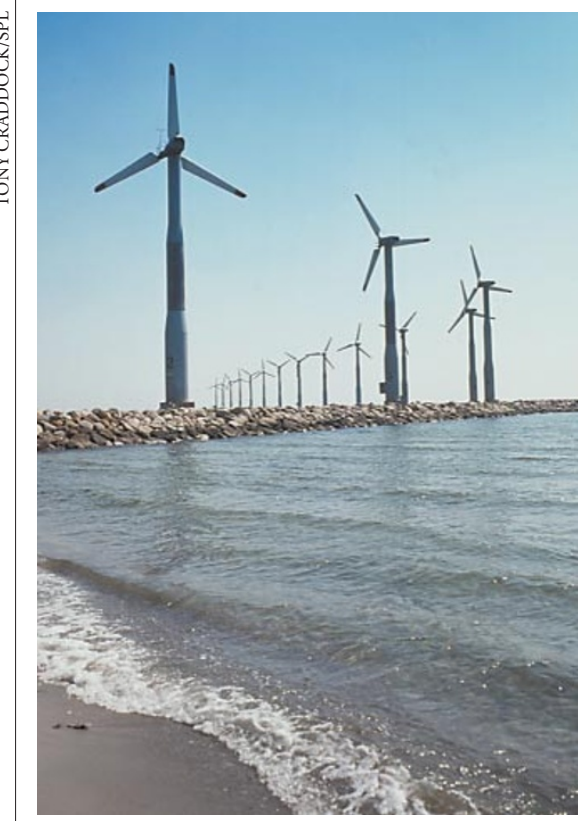

Clean power: wind turbines, such as these in Jutland, Denmark, are a rare sight in Britain.

\section{Brookhaven collider opens its quest for Big Bang conditions}

Steve Nadis, Boston

Two gold nuclei, hurtling in opposite directions around a 2.4-mile ring, crashed into each other last week, unleashing $10 \times 10^{12}$ electron volts of energy. This startling event marked the debut of the Relativistic Heavy Ion Collider (RHIC), as it came online at Brookhaven National Laboratory in New York.

Over the next few weeks, scientists hope to increase the accelerator's power to generate collisions releasing about $40 \times 10^{12}$ electron volts of energy. The aim is to simulate the conditions that existed during the first few microseconds after the Big Bang.

"RHIC can produce the largest centre of mass energy achieved by any accelerator, which makes it the best machine for studying the birth of nuclear matter in the Universe," says Tom Kirk, Brookhaven's associate director for high-energy and nuclear physics.

Researchers at the collider are trying to create a plasma of unattached quarks and gluons - the state of matter thought to have existed just after the Big Bang. They want to study the 'phase transition' that occurs as these particles combine to form protons and neutrons.

In February, scientists using the Super Proton Synchrotron (SPS) at the European Laboratory for Particle Physics (CERN) in Geneva announced they had found "compelling evidence" for the quark-gluon plasma (see Nature 403, 581; 2000). But the SPS did not generate enough energy for researchers to see the plasma directly.

The RHIC, which is about 10 times more powerful, "should produce the energy unequivocally needed to see the plasma”, says Kirk. The collider will yield temperatures well above one trillion degrees kelvin at the site of collision.

RHIC scientists will scour the rubble left by the ion collisions for clues to the plasma's existence. One tell-tale sign would be gamma-ray radiation produced by interactions of unconfined, high-energy quarks in the plasma. "That would certainly be a smoking gun," says Brookhaven physicist Tom Ludlam. Other direct evidence of the plasma's existence could come from electrons emerging from the plasma before it cools and reverts to ordinary nuclear matter. This cooling is very quick -
Collider scope? An end view of a collision of two gold nuclei at Brookhaven's RHIC collider.

the plasma is expected to last about $10^{-23}$ seconds.

The researchers also hope to find out the precise value of the critical temperature at which the quarks in protons and neutrons become unconfined - or, conversely, the into nucleons. And by measuring specific properties of the quark-gluon plasma, such as its temperature, density and entropy, they plan to test key predictions of quantum chromodynamics, the theory describing the strong nuclear force that joins quarks with gluons.

The RHIC machine was switched on after a concerted effort by Brookhaven officials to allay public fears of doomsday scenarios stirred up by alarmist news coverage. These media accounts suggested that the dense plasma created in the RHIC's high-energy collisions could produce a miniature black hole or a previously unseen form of nuclear matter called 'strange matter' — either of which might, according to the scare stories, quickly devour the planet. A panel of physicists dismissed these concerns in a report issued last autumn.

The current experiment at the RHIC is scheduled to run until August. The machine will eventually be superseded by the 30times more powerful A Large Ion Collider Experiment (ALICE) at CERN's Large Hadron Collider, which is due to be started up in 2005. "But there is a lot to learn before ALICE is turned on,” says Ludlam. "This really is unexplored territory." temperature at which free quarks coalesce 